\title{
Priming, a Promising Practical Approach to Improve Seed Germination and Plant Growth in Saline Conditions
}

\author{
Hadi Pirasteh-Anosheh ${ }^{1 *}$, Seyedeh Elahe Hashemi ${ }^{2}$ \\ ${ }^{1}$ National Salinity Research Center, Agricultural Research, Education and Extension Organization \\ Yazd, Iran \\ h.pirasteh.a@gmail.com \\ ${ }^{2}$ Faculty of Agriculture, Vali-e-Asr University of Rafsanjan \\ Rafsanjan, Iran \\ ${ }^{*}$ Corresponding author's email: elahe.hashemi1 [AT] gmail.com
}

\begin{abstract}
Salinity as a major constrain of plant productivity affects growth and development at any stage of growth cycle. Under saline conditions, rapid and uniform germination of plants would be necessary to achieve enhanced quality and potential yield. In such situation, seed priming could be an important approach to increase plant germination, growth and consequently yield. Priming is defined as seed presowing in solutions that allow them to imbibe water to improve the first stage of germination; however, this prevents radical protrusion through seed coat. Seed priming improves establishment in many plant species, and include hydro-priming, osmo-priming, halo-priming, thermo-priming and hormo-priming. Overall, accelerated biochemical and physiological process such cell division and starch hydrolysis, induced $\alpha$-amylase activity, greater germination rate, less $\mathrm{Na}^{+}$and higher $\mathrm{K}^{+}$accumulation and induced antioxidative system might be some mechanisms for salinity tolerance in primed plants. Since shortage of water availability due to osmotic stress is the first phase in salt stress, so one of the major mechanisms for improved germination and growth in primed seeds is accelerated water imbibition under saline conditions. In this paper, different seed priming strategies are examined and comprised in different plants growing in saline conditions. Since different types of seed priming have positive effects on germination, emergence, growth, yield as well as biochemical traits and quality of plants, it seems that seed priming could be promising approach for improved salinity tolerance in future world with changed climate. More researches on detail of seed priming for each agent is needed for each plant.
\end{abstract}

Keywords---- Halopriming, hormopriming, hydropriming, osmopriming, salt stress

Abbreviations: ABA- Abscisic acid, GA- Gibberellic acid, IAA- Indole-3-acetic acid, IBA- Indole-3-butyric acid, $\mathrm{K}^{+}$ Potassium, $\mathrm{Na}^{+}$- Sodium, NAA- Naphthaleneacetic acid, PEG- Polyethylene glycol, SA: Salicylic acid

\section{INTRODUCTION}

Environmental stresses reduce the quality and quantity of agricultural production. In addition, abiotic stresses reduce crop yield by $71 \%$, which estimated that potential yield loss is $20 \%$ by salinity (Pirasteh-Anosheh et al., 2016b). Salinity is a major factor limiting crop production in the world. Pirasteh-Anosheh et al. (2016b) believed that salt stress is one the most important abiotic stresses that adversely affecting plant growth and development and crop yield. Many of scientists and the experts believe salinity and drought are equally important in having adverse effects on plants and could not say that one being more important than the other. However, the author believed salinity could be more important than drought, because salinity can occur anywhere, even though the water resources are not limited.

Plants that grow on saline soils are encountered with soil solutions exhibiting diverse ionic compositions (ionic effects): varying proportions of $\mathrm{Na}^{+}, \mathrm{Ca}^{2+}, \mathrm{Mg}^{2+}, \mathrm{K}^{+}, \mathrm{SO}^{2-}, \mathrm{CO}^{2-}, \mathrm{HCO}^{3-}$ and $\mathrm{Cl}^{-}$and other ions and a wide range in the concentrations of dissolved salts (osmotic effect): concentrations fluctuate because of changes in water source, drainage, evapotranspiration, hydrostatic pressures, etc. (Ashraf and Harris, 2004; Negrao et al., 2017). Ashraf and Harris (2004) categorized the deleterious effects of salt stress on crop growth into osmotic stress, imbalance of ions, impact of specific ions and a combination of these factors.

Salt tolerance is the ability of plants to grow and develop their life cycles in a medium containing high percentage of soluble salts (Maas and Hoffman, 1977; Pirasteh-Anosheh et al., 2016b). Plants use extra biochemical and molecular mechanisms to overcome salinity. The former appears to involve alterations in many biochemical pathways, while the latter involves changes that protect major mechanisms such as photosynthesis and respiration (Parida and Das, 2005). 
Large body of researches have studied seed priming for improving seed germination and plant growth in saline conditions, and there is a need to deduction of their results for better decision. Therefore, the aim of this study is examination of different seed priming strategies and comparison in different plants that grown in saline conditions.

\section{SEED PRIMING FOR HIGHER SALINITY TOLERANCE}

Plants experience salt stress at different growth stages, such as germination, vegetative and reproductive growth. Under stressful environments, rapid and uniform germination of crops, particularly of annuals, is necessary to achieve enhanced quality and yield potential (Pirasteh-Anosheh et al., 2014). An important approach to increase crop yield under salt stress is seed invigoration. Seed invigoration strategies include hydropriming, osmopriming, halopriming, thermopriming and hormopriming. Plant establishment is improved by seed priming in many crop species. Priming is defined as seed pre-sowing in solutions that allow them to imbibe water to improve the first stage of seed germination; however, this prevents radical protrusion through the seed coat (Ellouzi et al., 2017).

\section{HYDROPRIMING}

In hydro-priming, seeds are soaked in water before sowing and this may or may not be followed by air-drying of the seeds (Pill and Necker, 2001). Improvement in salt tolerance of plants following hydro-priming has been observed in many studies. Hamidi et al. (2013) reported that the effect of hydro-priming on the germination percentage of wheat was more than that of the other priming types. However, its effect on shoot height was equal to and on leaf area was less than that of the other priming treatments. The mechanisms that improve plant growth and seed yield in saline or non-saline conditions by application of this simple technique are not yet clear (Ashraf et al., 2008).

\section{OSMOPRIMING}

In osmo-priming (osmo-conditioning or osmotic conditioning), seeds are soaked for a certain time period in solutions of sugars, polyethylene glycol (PEG), glycerol, sorbitol or mannitol followed by air-drying before sowing. The low water potential of these solutions causes partial seed imbibition, then initial metabolic processes are activated; however, germination does not proceed (Pill and Necker, 2001). Pirasteh-Anosheh and Hamidi (2013) reported that the percentage of germination, radicle and seedling length in rapeseed (Brassica napus) was significantly affected by application of PEG in seed priming. Seed priming with PEG had a higher effect on radicle length. However, in some experiments it was shown that PEG significantly reduced germination percentage, but increased seedling growth of sunflower (Hamidi and Pirasteh-Anosheh, 2013). Osmo-priming not only improves seed germination, but also enhances general crop performance under normal or salt stress environments. Application of $20 \%$ PEG-8000 for 2 days at $10^{\circ} \mathrm{C}$ enhanced germination, seedling growth, and dry matter under saline conditions in Italian ryegrass (Lolium multiflorum) and sorghum (Sorghum bicolor) (Hur, 1991).

\section{HALOPRIMING}

Halo-priming (soaking seed in solutions of inorganic salts) has been shown to have a significant and positive effect on germination, establishment, and growth in saline conditions (Ashraf et al., 2008). Hamidi et al. (2013) observed that two seed priming types: halo-priming $\left(\mathrm{KNO} 3, \mathrm{KH}_{2} \mathrm{PO}_{4}\right.$ and $\left.\mathrm{N}+\mathrm{P}\right)$ and hydro-priming increased germination percentage, seedling and radicle length, plant height and leaf area of wheat (Triticum aestivum). The best combinations for $\mathrm{KNO}_{3}$, $\mathrm{KH}_{2} \mathrm{PO}_{4}$ and $\mathrm{N}+\mathrm{P}$ were $100 \mathrm{mM}, 500 \mathrm{mM}, 50 \mathrm{mM}+10 \mathrm{mM}$, respectively. Halo-priming improves seedling emergence as well as subsequent plant growth, thereby, enhancing final plant yield. Ashraf et al. (2008) found that pre-soaking seed in solutions of inorganic salts improved growth and yield in many plants such as broad bean (Vicia faba), wheat, soybean (Glycine max), Pennisetum americanum and Sorghum bicolor under saline conditions. Pirasteh-Anosheh et al. (2011) showed that urea priming led to more germination and growth compared to other priming types. The effect of halopriming on proline content was not significant. These authors concluded that seedling establishment and root development were improved by using $\mathrm{KNO}_{3}$ and urea in saline conditions.

\section{THERMOPRIMING}

Thermo-priming is defined as exposing seeds to low or high temperatures to improve seed germination and seedling establishment in stressful conditions. It is indicated that seed germination of some species is positively improved by lowtemperature treatment (Ashraf and Foolad, 2005). It is also interesting to know that seed presowing treatment with some specific temperatures improves later plant growth and development as well as seed germination and seedling emergence (Ashraf et al. 2008). It has been reported that chilling treatment of Passiflora incarnata (Tavarini et al., 2018) and pearl millet (Pennisetum glaucum) (Ashraf et al., 2003) seeds resulted in enhanced germination under salt stress. The role of temperature treatment in germination, growth and yield of different crops in salt stress remains unclear.

\section{HORMOPRIMING}

Under abiotic stress conditions, the application of plant growth regulators (PGRs) as seed priming may overcome much of the internal PGRs deficiency and lead to alleviation of the inhibitory effects of abiotic stress (Ashraf and Foolad, 2005; Pakar et al., 2016; Pirasteh-Anosheh et al., 2016a). Pretreatment of seeds with optimal concentrations of PGRs 
(hormo-priming) such as chlormequat chloride, salicylic acid, auxins, gibberellins, kinetin, abscisic acid, polyamines, ethylene, brassinolide, triacontanol and ascorbic acid can effectively promote seed establishment, plant growth and development, and crop production in saline and non-saline conditions (Pirasteh-Anosheh et al., 2014). Hormo-priming beneficial effects in plant development and production in stressful conditions might be associated with improved nutrient availability as well as increased plant physiological process and root proliferation (Ashraf and Foolad, 2005).

Afria et al. (1998) reported that cycocel primed guar (Cyamopsis tetragonoloba L.) plants $\left(1.5 \mathrm{~g} \mathrm{~L}^{-1}\right)$ had higher growth and yield as well as reduced transpiration under salt stress conditions. Furthermore, Kanp et al. (2009) showed that cycocel seed pretreatment markedly improved the capacity of seed storage and crop performance of pea (Pisum sativum L.) and horse gram (Dolichos biflorus L.). Pirasteh-Anosheh et al. (2014) reported that cycocel priming reduced adverse effects of the stress on seedling emergence and vegetative growth and improved the level of leaf free proline and chlorophyll content index in wheat, barley, maize, sunflower, safflower, and rapeseed. Cycocel priming, by diverting a major proportion of assimilates to the root, increased root to shoot dry weight ratio under all osmotic stress levels. Treating seed of sudan grass (Sorghum sudanense) with cycocel reduced adverse effects of salinity on the rate and percentage of germination (Ismaeil et al., 1993).

Presowing seed treatment with salicylic acid (SA) affects seed germination, however, there are different reports on the role of SA in the promotion or inhibition of germination. Pirasteh-Anosheh and Emam (2017) reported that in all times after sowing, SA-primed seeds had greater absorbed water with higher growth rate. SA-primed seedlings had higher germination, growth and $\mathrm{K}^{+}$and lower $\mathrm{Na}^{+}$. They also indicated that $\mathrm{SA}$-primed seedlings showed a greater $\mathrm{Na}^{+}$ storage factor, i.e., they kept more $\mathrm{Na}^{+}$in their roots. In another study, tomato seedlings pretreated with SA for 3 weeks showed a remarkable improvement in the activities of certain antioxidant enzymes, including superoxide dismutase, catalase and peroxidase, under salt stress (Szepesi et al., 2008). Szepesi (2006) indicated that pretreatment of tomato seedlings with SA resulted in a marked accumulation of $\mathrm{Na}^{+}$and compatible osmolytes consisting of glucose, fructose, sorbitol, and proline in the leaves of plants subjected to salt media. In fact, reduction in leaf water potential led to improved accumulation of abscisic acid (ABA) in the roots, enabling the plants to induce the ABA signal transduction pathways and gene expression under salt stress. In saline media, the SA-pretreated plants also produced higher amounts of compatible osmolytes such as glucose, fructose, sorbitol, and proline that improved plant growth and enhanced photosynthetic efficiency.

Brassinolide seed priming led to significant increases in germination parameters in Vigna mungo (Singh and Jakhar, 2018) as well as barley and common bean (Abd El-Fattah, 2007) under saline conditions. In the latter case, it was shown that BR seed priming caused accumulation in betaine (a potential osmoprotectant) and glutathione (a non-enzymatic antioxidant). Gibberellic acid seed priming (Ma et al., 2018) as well as auxins such as indole-3-acetic acid (IAA), indole3-butyric acid (IBA) and naphthaleneacetic acid (NAA) seed soaking (Ashraf et al., 2018) enhanced seed germination of wheat under salt stress. Gibberellic acid (GA) seed priming at different concentrations improved seed germination under saline conditions in wheat (Ulfat et al., 2017), wheat, rice and maize (Majeed et al., 2018), Soybean (Glycine max L.), (Jassal et al., 2017). Other plant growth regulators also have considerable effects on seed germination, growth, and yield, for example seed priming by ascorbic acid, mannitol and sorbitol in rice (Theerakulpisut et al., 2017), by kinetin in cucumber (Cucumis sativus L.) (Gurmani et al., 2018), and by kinetin in wheat (Iqbal and Ashraf, 2005a) and PAs in wheat (Iqbal and Ashraf, 2005b).

\section{CONCLUSIONS}

Seed priming could be considered as a practical method for increase plant production in saline conditions. Although, the mechanisms of these simple techniques are not yet fully clear, accelerated water imbibition and cell division, greater germination rate, less $\mathrm{Na}^{+}$and higher $\mathrm{K}^{+}$accumulation and induced antioxidative system may be some mechanisms for improved salinity tolerance. Different seed priming strategies have improved quantity and quality of a wide range of plants, therefore the use of this technique will be inevitable in the future. Nonetheless, use of different priming agents needs large-scale assessment.

\section{CONFLICT OF INTEREST}

The authors declare that there is no conflict of interest.

\section{REFERENCES}

- Abd El-Fattah RI. 2007. Osmolytes-antioxidant behavior in Phaseolus vulgaris and Hordeum vulgare with brassinosteroid under salt-stress. J Agric Environ Sci 2: 639-647.

- Afria BS, Nathawat NS, Yadav ML. 1998. Effect of cycocel and saline irrigation of physiological attributes, yield and its components in different varieties of Guar (Cyamopsis tetragonoloba L. Taub). Ind J Plant Physiol 3: $46-48$.

- Ashraf M, Kausar A, Ashraf MY. 2003. Alleviation of salt stress in pearl millet (Pennisetum glaucum (L.) R. Br.) through seed treatments. Agron 23: 227-234.

- Ashraf M, Harris PJC. 2004. Potential biochemical indicators of salinity tolerance in plants. Plant Sci 166: 3-16. 
- $\quad$ Ashraf M, Foolad MR. 2005. Pre-sowing seed treatment - a shotgun approach to improve germination, plant growth, and crop yield under saline and non-saline conditions. Adv Agron 88: 223-271.

- Ashraf M, Athar HR, Harris PJC, Kwon TR. 2008. Some prospective strategies for improving crop salt tolerance. Adv Agron 97: 45-110.

- Ashraf MA, Akbar A, Askari SH, Iqbal M, Rasheed R, Hussain I. 2018. Recent advances in abiotic stress tolerance of plants through chemical priming: an overview. In Rakshitm A, Singh HB (eds) Advances in seed priming. Springer, Singapore, pp. 51-79.

- Ellouzi H, Sghayar S, Abdelly C. 2017. $\mathrm{H}_{2} \mathrm{O}_{2}$ seed priming improves tolerance to salinity; drought and their combined effect more than mannitol in Cakile maritima when compared to Eutrema salsugineum. J Plant Physiol 210: 38-50.

- Gurmani AR, Khan SU, Ali A, Rubab T, Schwinghamer T, Jilani G, Zhang J. 2018. Salicylic acid and kinetin mediated stimulation of salt tolerance in cucumber (Cucumis sativus L.) genotypes varying in salinity tolerance. Hort Environ Biotech 59: 461-471.

- Hamidi R, Pirasteh-Anosheh H. 2013. Comparison effect of different seed priming methods on sunflower germination and seedling growth. Int J Agron Plant Prod 4: 1247-1250.

- Hamidi R, Pirasteh-Anosheh H, Izadi M. 2013. Effect of seed halo-priming compared with hydro-priming on wheat germination and growth. Int J Agron Plant Prod 4: 1611-1615.

- Hur SN. 1991. Effect of osmoconditioning on the productivity of Italian ryegrass and sorghum under suboptimal conditions. Kor J Animal Sci 33: 101-105.

- Iqbal M, Ashraf M. 2005a. Presowing seed treatment with cytokinins and its effect on growth, photosynthetic rate, ionic levels and yield of two wheat cultivars differing in salt tolerance. J Integr Plant Biol 47: 1315-1325.

- Iqbal M, Ashraf M. 2005b. Changes in growth, photosynthetic capacity and ionic relations in spring wheat (Triticum aestivum L.) due to pre-sowing seed treatment with polyamines. Plant Growth Regul 46: 19-30.

- Ismaeil SM, Khafagi OMA, Kishk ET, Sohsah SM. 1993. Effect of some seed hardening treatments on germination, growth and yield of sudangrass grown under saline conditions. Desert Inst Bull Egypt 43: 221242.

- Jassal RK, Singh H, Kang JS. 2017. Yield and Yield Attributes of Soybean (Glycine max L.) as affected by Seed Priming. Int J Curr Microbiol App Sci 12: 4285-4293.

- Kanp UK, Das RK, Bhattacharjee A. 2009. Enhancement of storage potential of seeds and field performance of pea and horse gram by growth retardants. Legume Res 32: 7-12.

- $\quad$ Ma HY, Zhao DD, Ning QR, Wei JP, Li Y, Wang MM, Liang ZW. 2018. A multi-year beneficial effect of seed priming with gibberellic acid ${ }_{-3}\left(\mathrm{GA}_{3}\right)$ on plant growth and production in a perennial grass, Leymus chinensis. Sci Rep 8: 1-9.

- Maas EV, Hoffman GJ. 1977. Crop salt tolerance-current assessment. J Irrig Drain Divis 103: 115-134.

- Majeed A, Muhammad Z, Islam S, Ahmad H. 2018. Salinity imposed stress on principal cereal crops and employing seed priming as a sustainable management approach. Acta Ecol Sinica 39: 280-293.

- Negrao S, Schmockel SM, Tester M. 2017. Evaluating physiological responses of plants to salinity stress. Ann Bot 119: 1-11.

- Pakar N, Pirasteh-Anosheh H, Emam Y, Pessarakli M. 2016. Barley growth, yield, antioxidant enzymes, and ion accumulation affected by PGRs under salinity stress conditions. J Plant Nutr 39(10): 1372-1379.

- $\quad$ Parida AK, Das AB. 2005. Salt tolerance and salinity effects on plants: a review. Ecotoxicol. Environ Saf 60: 324-349.

- Pill WG, Necker AD. 2001. The effects of seed treatments on germination and establishment of Kentucky bluegrass (Poa pratense L.). Seed Sci Technol 29: 65-72.

- Pirasteh-Anosheh H, Sadeghi H, Emam Y. 2011. Chemical priming with urea and $\mathrm{KNO}_{3}$ enhances maize hybrids (Zea mays L.) seed viability under abiotic stress. J Crop Sci Biotech 14: 289-295.

- Pirasteh-Anosheh H, Hamidi R. 2013. Does seed chemical priming improves germination and early growth of oil rapeseed? Int J Agron Plant Prod 4: 805-808.

- Pirasteh-Anosheh H, Emam Y, Ashraf M. 2014. Impact of cycocel on seed germination and growth in some commercial crops under osmotic stress conditions. Arch Agron Soil Sci 60(9): 1277-1289.

- Pirasteh-Anosheh H, Emam Y, Khaliq A. 2016a. Response of cereals to cycocel application. Iran Agric Res 35: $1-12$.

- Pirasteh-Anosheh H, Ranjbar G, Pakniyat H, Emam Y. 2016b. Physiological mechanisms of salt stress tolerance in plants: An overview. In: Azooz MM, Ahmad P (eds) Plant-environment interaction: responses and approaches to mitigate stress. John Wiley Sons, Ltd, Chichester, pp. 141-160.

- Pirasteh-Anosheh H, Emam Y. 2017. Induced salinity tolerance and altered ion storage factor in Hordeum vulgare plants upon salicylic-acid priming. Iran Agric Res 36: 41-48.

- Singh S, Jakhar S. 2018. 24-Epibrassinolide mediated changes on germination and early seedling parameters of Vigna Mungo (L). Hepper var. Shekhar-2 under salinity stress. Pertan J Trop Agric Sci 41: 485-494. 
- Szepesi A. 2006. Salicylic acid improves the acclimation of Lycopersicon esculentum Mill. L. to high salinity by approximating its salt-stress response to that of the wild species L. pennellii. Acta Biol Szeged 50: 177-177.

- Szepesi A, Poor P, Gemes K, Horvath E, Irma T. 2008. Influence of exogenous salicylic acid on antioxidant enzyme activities in the roots of salt-stressed tomato plants. Acta Biol Szeged 52: 199-200.

- Tavarini S, Ceccarini L, Lauria G, Angelini LG. 2018. Evaluation of different pre-germination treatments, temperature and light conditions, to improve seed germination of Passiflora incarnata L. Conven. Ital Soc Agron New Agric 1: 61-63

- Theerakulpisut P, Kanawapee N, Panwong B. 2017. Seed priming alleviated salt stress effects on rice seedlings by improving $\mathrm{Na}^{+} / \mathrm{K}^{+}$and maintaining membrane integrity. Inter J Plant Biol 7: 53-58.

- Ulfat A, Majid SA, Hameed A. 2017. Hormonal seed priming improves wheat (Triticum aestivum L.) Field performance under drought and non-stress conditions. Pak J Bot 49(4): 1239-1253. 